\title{
Meaningful and Sustained Weight Loss and Improvement of Lipid Profile in Hypogonadal Men on Long-Term Treatment with Testosterone Undecanoate (TU) Injections are Independent of Age: Observational Data from Two Registry Studies
}

\author{
Saad $F^{1,2}$, Haider $A^{3}$, Yassin $A^{2,4,5}$, Doros $G^{6}$, Traish $A^{7}$ \\ ${ }^{1} \mathrm{Global}$ Medical Affairs Andrology, Bayer Pharma, Berlin, Germany \\ 2Gulf Medical University, Ajman, UAE \\ 3Private Urology Practice, Bremerhaven, Germany \\ Institute for Urology and Andrology, Norderstedt, Germany
5Dresden International University. Dresden, Germany \\ ${ }^{6}$ Department of Epidemiology and Statistics, Boston University School of Public Health, Boston, Mass, USA \\ Departments of Biochemistry and Urology, Boston University School of Medicine, Boston, Mass, USA
}

\begin{abstract}
Introduction
Improvements of anthropometric and metabolic parameters on long-term testosterone replacement therapy (TRT) from our registry studies have been reported in 2013 (Saad, Obes; Yassin and Doros, Clin Obes; Traish, Int J Clin Pract).

Methods

561 hypogonadal men from both registry studies were divided into age groups $\leq 65$ (Group $A, n=450$ ) and $>65$ years (Group B, $n=111$ ). All men were treated with three-monthly TU injections for up to 6 years.
\end{abstract}

\section{Results}

Mean weight $(\mathrm{kg})$ decreased from $102.52 \pm 15.56$ to $90.15 \pm$ 9.69 in Group A and from $102.83 \pm 15.64$ to $95.35 \pm 9.03$ in Group B. Model-adjusted mean change from baseline was $14.78 \pm 0.35$ and $-15.14 \pm 0.71 \mathrm{~kg}$, resp. Percent change from baseline was $-13.56 \pm 7.56 \%$ in Group A and $-13.28 \pm$ $7.14 \%$ in Group B. Waist circumference $(\mathrm{cm})$ decreased from $106.54 \pm 9.03$ to $98.26 \pm 7.1$ in Group A and from $108.95 \pm$ 10.75 to $100.72 \pm 9.45$ in Group B. The mean change from baseline was $9.34 \pm 0.2 \mathrm{~cm}$ in Group A and $10.45 \pm 0.47 \mathrm{~cm}$ in Group B.

Body mass index (BMI; $\mathrm{kg} / \mathrm{m}^{2}$ ) decreased from $32.58 \pm 5.08$ to $29.02 \pm 3.01$ in Group A and from $32.84 \pm 4.86$ to $30.35 \pm$ $2.61 \mathrm{in}$ Group B. The mean change from baseline was -4.72 \pm 0.11 and $-4.81 \pm 0.22 \mathrm{~kg} / \mathrm{m}^{2}$, respectively ( $p<0.0001$ for all).

Total cholesterol (TC, $\mathrm{mg} / \mathrm{dl}$ ) decreased from $268.92 \pm 45.95$ to $193.56 \pm 16.58$ in Group A and from $268.44 \pm 52.69$ to $191.69 \pm 21.8$ in Group B, LDL (mg/dl) from $159.87 \pm 36.7$ to $119.81 \pm 34.87$ in Group A and from $162.48 \pm 31.63$ to $120.86 \pm 33.56$ in Group B, triglycerides ( $\mathrm{mg} / \mathrm{dl}$ ) from $262.35 \pm 73.16$ to $192.1 \pm 34.4$ in Group A and from $266.9 \pm$ 84.37 to $192.27 \pm 32.16$ in Group B. HDL (mg/dl) increased from $48.91 \pm 17.33$ to $59.55 \pm 17.66$ in Group $A$ and from $51.64 \pm 16.56$ to $61.99 \pm 16.87$ in Group B. TC:HDL ratio improved from $6.15 \pm 2.42$ to $3.54 \pm 1.04$ in Group $A$ and from $5.67 \pm 2.09$ to $3.32 \pm 0.91$ in Group B ( $<<0.0001$ for all).

\section{Conclusions}

TRT in hypogonadal men resulted in meaningful and sustained weight loss and improvement of lipid profile independent of age.
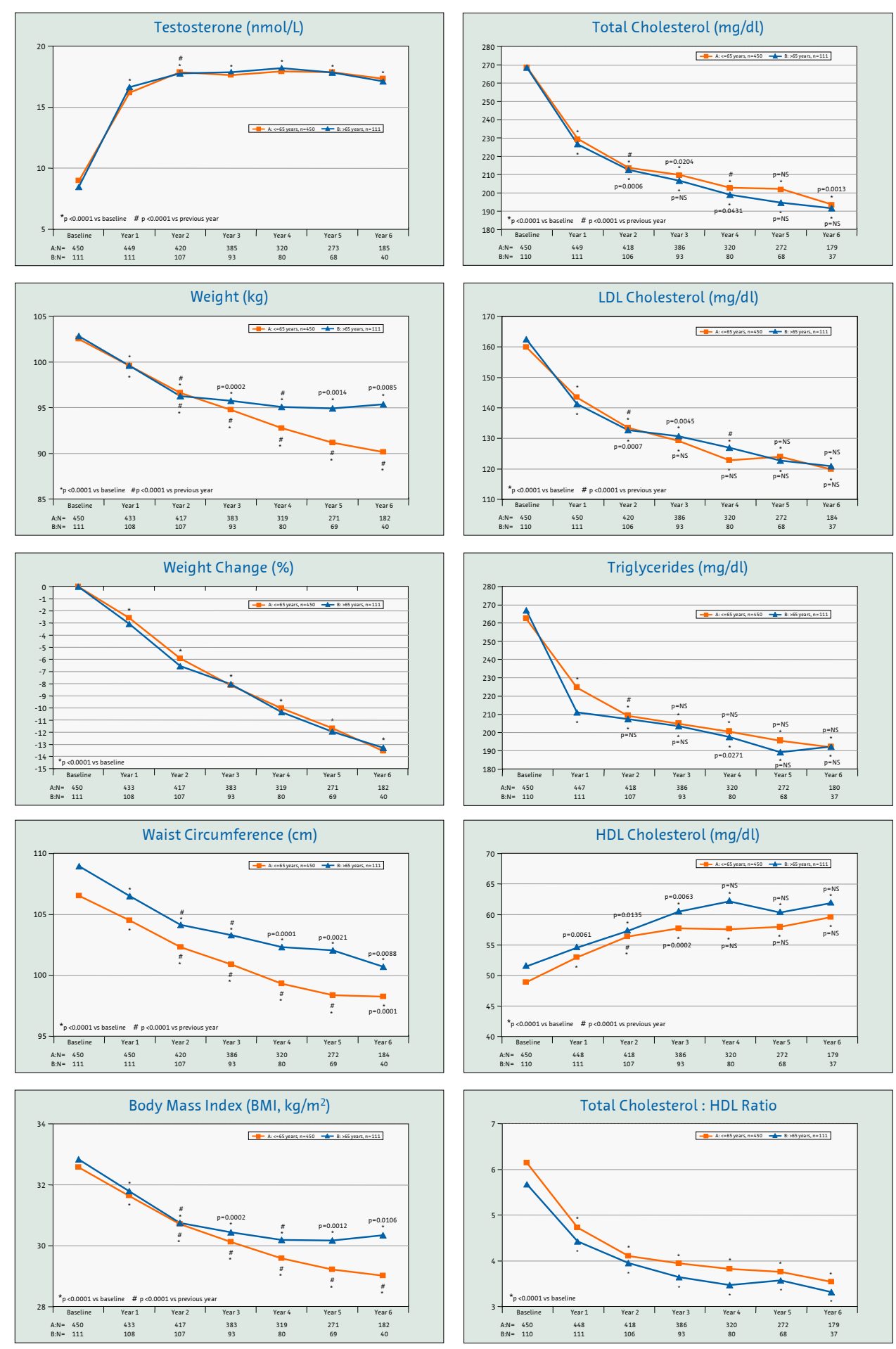